\title{
Critical Break Length of Floor Aquiclude During Longwall Mining Above Confined Aquifer
}

\author{
Baohua Guo ${ }^{1,2,3,}$, Feng Jiao ${ }^{1}$, Xiaoyu Yang ${ }^{4}$ \\ ${ }^{1}$ Collaborative Innovation Center of Coal Work Safety, Jiaozuo, China \\ ${ }^{2}$ School of Energy Science and Engineering, Henan Polytechnic University, Jiaozuo, China \\ ${ }^{3}$ Key Laboratory of Safety and High-Efficiency Coal Mining, Ministry of Education (Anhui University of Science and Technology), Huainan, \\ China \\ ${ }^{4}$ Shendong Coal Group Company, China Shenhua Energy Company Limited, Erdos, China
}

\section{Email address:}

guobaohua@139.com (Baohua Guo)

${ }^{*}$ Corresponding author

\section{To cite this article:}

Baohua Guo, Feng Jiao, Xiaoyu Yang. Critical Break Length of Floor Aquiclude During Longwall Mining Above Confined Aquifer. Earth Sciences. Vol. 6, No. 6, 2017, pp. 149-156. doi: 10.11648/j.earth.20170606.17

Received: September 5, 2017; Accepted: September 21, 2017; Published: November 2, 2017

\begin{abstract}
Floor water inrushes not only cause heavy casualties and property losses, but seriously restrict the production of coal mines. The aquiclude was simplified as the fixed - fixed beam under the uniform load, and critical break length formula of floor aquiclude in three failure modes including bending failure, shear failure and buckling of pressure bar were established. Then the critical lengths of aquiclude in three failure modes were calculated according to the geological and mining conditions of 15031 panel in Jiulishan coalmine. The results show that the critical break length in bending failure is the smallest, while the critical length in shear failure mode is the biggest. And failures of fixed - fixed beam in three failure modes all occur at two ends so that water inrush from floor may occur at open-off cut or working face. Additionally, three critical break lengths increase with aquiclude thickness but decrease with confined aquifer pressure. According to the calculated results, water inrush may occur at the working face or open-off cut when mining advance reaches $12.47 \mathrm{~m}$, and thus three control measures of lowering aquifer pressure, increasing aquiclude thickness and shortening the distances of first and interval weighting of main roof were discussed. The conclusions can provide references to control water inrush from floor aquifer in coal mines.
\end{abstract}

Keywords: Coal Mine, Water Inrush, Floor Aquiclude, Fixed - fixed Beam, Critical Break Length

\section{Introduction}

China is one of the most serious countries suffering from water inrush disasters, which not only caused heavy casualties and property losses, but also seriously restricted the production of coal mines. According to statistics, $60 \%$ of coal mines in China are threatened by the confined aquifer more or less. For example, more than 230 coal mines are threatened by the confined aquifer only in northern China, which results in about $40 \%$ of coal resources can not be exploited. The mechanism of mine water inrushes in coal mines in China differs considerably from that in other countries. In China, most water inrushes occur from floor strata, where the water inrush sources are karstic limestone aquifers ${ }^{[1]}$. There are two types of water inrush from floor that one is caused by geological structures such as faults and karst collapsed column which are frequent to occur in China and the other is caused by failures of floor aquiclude during the mining process. The latter type of water inrush presents an ascending tendency in these years as the confined aquifer pressure becomes higher with the decrease of shallow coal resource. For example, the pressure of confined aquifer is generally 2 - $6 \mathrm{MPa}$ in Jiaozuo coal field in Henan Province [2]. Thus, aquiclude is the key barrier to prevent mining excavation from water inrush during coal mining above confined aquifer. The formation of water inrush channels dominates whether inrush happens when there are no geological structures such as faults and karst collapsed 
column existing in the floor strata, so the study on failure characteristics of aquiclude is quite crucial to inquiry water inrush mechanism of "intact" floor.

Many scholars carried out a lot of researches on water inrush mechanism, and put forward various theories and methods. Wang et al [3] presented a micromechanics-based coupled damage and flow modeling approach to simulate the progressive development of fractures and the associated water flow in the floor strata during mining above a confined aquifer. Zhang [4] applied the finite element method coupled with stress-dependent permeability to analyze hydraulic conductivity enhancement due to coal extraction. Yang et al [5] presented a fully coupled flow-stress-damage model to simulate the progressive development of fractures and the associated groundwater flow under incremental loading conditions resulted from mining processes. Kong et al [6] used a theory of seepage instability to estimate the harmfulness of water-inrush from a coal seam floor in a particular coal mine of Xuzhou Mining Group. Zhu et al [7] developed a numerical model of the key strata by using Dilian Mechsoft's Realistic Failure Process Analysis (RFPA2D) program to predict failure modes and to establish rules for safe mining above the aquifer. Jiang [8] established a numerical model of water-resisting strata using the analytical module of fluid-structure interaction of FLAC to analyze the destruction of water-resisting strata in floor of coal seams being mined.

In the aspect of on site monitoring, Jian et al [9] used a high-precision micro-seismic monitoring technique to monitor the continuous, dynamic failure of an inclined coal seam floor. Huang et al [10] characterized the hydraulic conductivity of rock formations between deep coal and aquifers using injection tests. Li et al [11] used Direct Current (DC) resistivity method for routine detection, advanced detection and real-time monitoring of water-bearing structures to avoid water inrush hazard in underground engineering.

In summary, scholars have already carried out thorough studies on water inrush mechanism by simulating or monitoring the failure process of coal seam floor. However, the study on break mechanism of the aquiclude as a bearing beam is rare. Consequently, the mechanical model of taking floor aquiclude as fixed - fixed beam was established, and then the critical break length formulas of floor aquiclude in three failure modes including bending failure, shearing failure and buckling of pressure bar were given. At last, the above formulas were applied to calculate the critical break lengths of floor aquiclude in Jiulishan coalmine, Jiaozuo group.

\section{Mechanical Model of the Floor Aquiclude}

Strata section of longwall mining panel is shown in Figure 1, from which we can know that surrounding rock strata include roof, coal seam and floor, while floor consists of confined aquifer, aquiclude and other rock layers. When a coal seam is near horizontal or gently inclined, the floor aquiclude can be regarded as a fixed - fixed rectangular beam as shown in Figure 2, where the total thickness of aquiclude and other rock layers between coal seam and aquiclude is $h$; the uniform confined aquifer pressure is $q$. Thus the gravity of aquiclude is $\gamma h$, and the equivalent water pressure of the fixed - fixed beam $q_{\text {eff }}$ is:

$$
q_{e f f}=q-\gamma h
$$

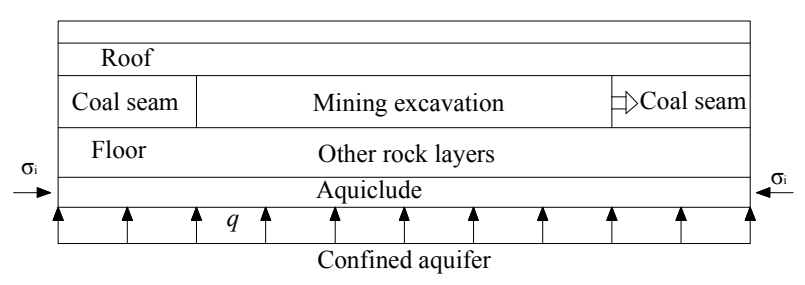

Figure 1. Strata Section of Long Wall Mining Panel.

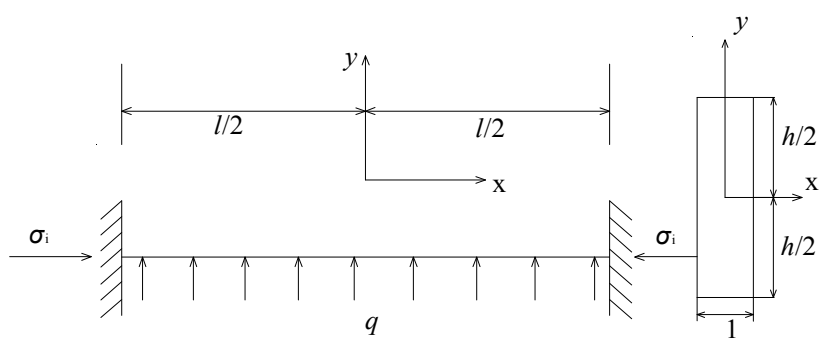

Figure 2. Fixed -fixed Beam Model of Floor Aquiclude.

\section{Critical Break Length of Floor Aquiclude}

\subsection{Bending Failure}

\subsubsection{Single Layered Aquiclude}

The bending moment $M$ of fixed - fixed beam under the uniform load $q_{\text {eff }}$ is expressed as

$$
M=-\frac{1}{2} q_{e f f} x^{2}+\frac{1}{24} q_{e f f} l^{2}
$$

Where $l$ is the length of the beam.

From formula (2) we can know that the bending moment of fixed - fixed beam gets the maximum when $x=l / 2$ and $M_{\max }$ is

$$
M_{\max }=-\frac{1}{12} q_{e f f} l^{2}
$$

When straight beam is in pure bending state, the normal stress of the point on cross-section is

$$
\sigma_{\max }=\frac{M}{I_{z}} y_{\max }
$$

Where $I_{z}$ is inertia moment of the cross-section to the neutral axis. For a rectangular cross-section beam $I_{z}$ is 
defined as follows:

$$
I_{Z}=\frac{h^{3}}{12}
$$

Formula (4) shows the maximal tension of beam locates at the farthest point on cross-section from the neutral axis; because the neutral axis is the symmetry axis of cross-section, the maximum normal stress is at the cross line between the cross-section and the lower surface $\left(\mathrm{y}_{\max }=-\frac{h}{2}\right)$, which is

$$
\sigma_{\max }=\frac{q_{e f f} l^{2}}{2 h^{2}}
$$

Thus, bending failure will occur at two ends of the beam firstly. But once the ends are broken, the fixed - fixed beam model will become the freely supported beam model. For a freely supported beam subjected to uniform loads, the maximal bending moment locates at the middle of the beam and the maximum is $1 / 8 q l^{2}$. But the beam may not continue to break as the decrease of equivalent water pressure after either end is broken.

Because tensile strength of strata is relatively small, the floor aquiclude will be easy to break when following condition is met,

$$
\sigma_{\max } \geq \sigma_{t}
$$

Where $\sigma_{\mathrm{t}}$ is the tensile strength of floor aquiclude, MPa. Bring Formula (6) into Formula (7), that is

$$
\frac{q^{e f f} l_{1}^{2}}{2 h^{2}} \geq \sigma_{t}
$$

Where $l_{1}$ is the critical break length in bending failure mode, $\mathrm{m}$. Therefore,

$$
l_{1} \geq h \sqrt{\frac{2 \sigma_{t}}{q_{e f f}}}
$$

\subsubsection{Multi-layered Aquiclude}

When there are other rock layers between aquiclude and the coal seam, water inrush will occur once break of aquiclude happens. Provided the number of layers is $n$, the bending moment of each layer is the same, and there is no horizontal dislocation between the adjacent layers, the bending break length of the combined beam could be expressed as follows:

$$
l_{1} \geq \sum_{i=1}^{n} h_{i} \sqrt{\frac{2 \sigma_{t}}{q_{e f f}}}
$$

\subsection{Shear Failure}

\subsubsection{Single Layered Aquiclude}

Not only bending failure mode, but also shear failure mode should be considered when the critical break length of floor aquiclude is analyzed. As shown in Figure 2, the shear stress distribution is quite different along the long axial of the beam, and the maximum of shear load locates at both ends of the beam, which is

$$
T_{s \max }=\frac{1}{2} q_{\text {eff }} l
$$

The tensile stress $\sigma_{t}$ on every cross section of the beam as shown in Figure 2 is

$$
\sigma_{t}=\frac{M}{I_{z}} y
$$

Substituting Formula (2) and Formula (5) into Formula (12), we get tensile stress on the cross section as follows:

$$
\sigma_{t}=\frac{-12 q_{e f f} x^{2}+q_{e f f} l^{2}}{2 h^{3}} y
$$

While considering mohr-coulomb strength criterion for rockmass, shear stress $\tau$ on cross section is written as follow:

$$
\tau=\left(\sigma_{h}-\sigma_{t}\right) \tan \phi+c
$$

Where $\sigma_{h}$ is horizontal stress after excavation, $\mathrm{MPa} ; \varphi$ is friction angle of the aquiclude; $c$ is cohesion of the aquiclude, $\mathrm{MPa}$.

So, the shear resistance of the overall cross section is

$$
T_{r}=\int_{-\frac{h}{2}}^{\frac{h}{2}}\left[\left(\sigma_{h}-\sigma_{\mathrm{t}}\right) \tan \phi+c\right] d y=\left(\sigma_{h} \tan \phi+c\right) h
$$

From Formula (15), we know the shear resistance of every cross section along the long axis direction is all the same and thus whether the beam is broken or not depends on shear load distribution. Shear failures will appear at the ends of the beam as the maximum shear load locates there. Provided $T_{s \text { max }}>T_{r}$, we get

$$
\frac{1}{2} q_{e f f} l_{2} \geq\left(\sigma_{h} \tan \phi+c\right) h
$$

Further,

$$
l_{2} \geq \frac{2\left(\sigma_{h} \tan \phi+c\right) h}{q_{e f f}}
$$

Where $l_{2}$ is the critical break length in shear failure mode.

\subsubsection{Multi-layered Aquiclude}

When there are other rock layers between the aquifer and the coal seam, provided the number of layers is $n$, the bending moment of each layer is the same, and there is no horizontal dislocation between the adjacent layers, the critical break length of the combined beam in shear failure mode could be derived as follows. 
The shear resistance exerting on cross section of the beam end is

$$
T_{r}=\sum_{j=1}^{n}\left[\left(\sigma_{h} \tan \phi_{j}+C_{j}\right) h_{j}-\frac{q_{\text {eff }} l^{2}}{h^{3}}\left(\sum_{i=j+1}^{n} h_{i}-\sum_{i=1}^{j-1} h_{i}\right) h_{j} \tan \phi_{j}\right]
$$

Provided

$$
A=\sum_{j=1}^{n}\left(\sigma_{h} \tan \phi_{j}+C_{j}\right) h_{j}
$$

and

$$
B=-\sum_{j=1}^{n} \frac{q_{\text {eff }}}{h^{3}}\left(\sum_{i=j+1}^{n} h_{i}-\sum_{i=1}^{j-1} h_{i}\right) h_{j} \tan \phi_{j}
$$

Formula (18) can be written as follows:

$$
T_{r}=A+B l_{2}^{2}
$$

The critical break length in shear failure is

$$
l_{2}=\frac{q_{e f f} \pm \sqrt{q_{e f f}^{2}-16 A B}}{4 B}
$$

Based on formula (22), we can get the further answers:

(1) When $\phi$ is a constant, the floor above confined aquifer is regarded as one type of rock, so we can get $B=0$ and $A=\left(\sigma_{x} \tan \phi+C\right) h$.

(2) When $\phi$ is a variable value, and $B \neq 0$, critical break length is calculated as follows because it cannot be zero or negative.:

When $A>0$,

$$
l_{21}=\frac{q_{e f f}-\sqrt{q_{e f f}^{2}-16 A B}}{4 B}
$$

When $A<0$ and $B>0$,

$$
l_{22}=\frac{q_{e f f}+\sqrt{q_{e f f}^{2}-16 A B}}{4 B}
$$

When $A=0$,

$$
l_{23}=\frac{q_{e f f}}{2 B}
$$

\subsubsection{Comparison Between Critical Break Length in Bending and Shear Failure Modes}

To compare critical break length of floor aquiclude without other rock layers between coal seam and aquiclude in bending failure mode and in shear failure mode, Formula (9) and Formula (17) can be expressed as follows:

$$
\begin{gathered}
l_{1}^{2}=\frac{2 h^{2} \sigma_{t}}{q_{e f f}} \\
l_{2}^{2}=\frac{4\left(\sigma_{i h} \tan \phi+c\right)^{2} h^{2}}{q_{e f f}^{2}}
\end{gathered}
$$

If let $l_{1}^{2}>l_{2}^{2}$,

$$
\sigma_{t} \geq \frac{2\left(\sigma_{i h} \tan \phi+c\right)^{2}}{q_{e f f}}
$$

When Formula (28) holds, a shear failure tends to occur, otherwise, a bending failure tends to occur on the floor aquiclude.

\subsection{Buckling of Pressure Bar}

\subsubsection{Single Layered Aquiclude}

Provided the length of fixed - fixed beam is much longer than its thickness, the buckling failure of pressure bar may occur. Therefore, the stability of the fixed - fixed beam under the equivalent water pressure $q_{\text {eff }}$ and the horizontal stress $\sigma_{i h}$ need to be analyzed. Calculation sketch of buckling of pressure bar is also shown in Figure 2. The moment of fixed - fixed beam considering the horizontal stress $\sigma_{i h}$ is expressed as follow:

$$
M(x)=P w(x)-\frac{1}{2} q_{e f f} x^{2}+\frac{1}{24} l^{2}
$$

Where $P$ is horizontal load, $P=\sigma_{i h} h ; w$ is the deflection of pressure bar.

The differential equation of the deflection curve is

$$
E I w^{\prime \prime}=-M(x)
$$

Where $E$ is the elastic modulus of pressure bar.

Putting Formula (29) into Formula (30), we can obtain

$$
w^{\prime \prime}+K^{2} w=\frac{q}{2 E I} x^{2}-\frac{q l}{24 E I} x
$$

Where

$$
K^{2}=\frac{P}{E I}
$$

The general solution of the above differential equation can be expressed as follow:

$$
w(x)=A_{1} \cos k x+A_{2} \sin K x+\frac{q_{e f f}}{2 P} x^{2}-\frac{q_{e f f} l^{2}}{24 P}-\frac{q_{e f f} E I}{P^{2}}
$$

By applying the boundary conditions

$$
w\left( \pm \frac{l}{2}\right)=0,\left(\frac{d w}{d x}\right)_{x=0}=0
$$


We can get

$$
A_{1}=\left(\frac{q_{e f f} E I}{P^{2}}-\frac{q_{e f f} l^{2}}{12 P}\right) \sec \frac{K l}{2}, A_{2}=0
$$

So the deflection differential equation is expressed as follow:

$$
w(x)=\left(\frac{q_{e f f} E I}{P^{2}}-\frac{q_{e f f} l^{2}}{12 P}\right) \sec \frac{K l}{2} \cos K x+\frac{q_{e f f} x^{2}}{2 P}-\frac{q_{e f f} l^{2}}{24 P}-\frac{q_{e f f} E I}{P^{2}}
$$

From Formula (34), the maximum deflection occurs at the midpoint of the pressure bar, which is

$$
\omega_{\max 1}(x)=\omega(0)=\left(\frac{q_{e f f} E I}{P^{2}}-\frac{q_{e f f} l^{2}}{12 P}\right) \sec \frac{K l}{2}-\frac{q_{e f f} l^{2}}{24 P}-\frac{q_{e f f} E I}{P^{2}}
$$

Then putting Formula (36) into Formula (29), we can get

$$
M(x)=\left(\frac{q_{e f f} E I}{P}-\frac{q_{e f f} l^{2}}{12}\right) \sec \frac{K l}{2} \cos K x-\frac{q_{e f f} E I}{P}
$$

The maximum moment occurs at the midpoint or two ends of the pressure bar, which is

$$
M_{\max }(0)=\left(\frac{q_{e f f} E I}{P}-\frac{q_{e f f} l^{2}}{12}\right) \sec \frac{K l}{2}-\frac{q_{e f f} E I}{P}
$$

and

$$
M_{\max }\left( \pm \frac{l}{2}\right)=-\frac{q_{e f f} l^{2}}{12}
$$

Thus,

$$
M(0)-M\left( \pm \frac{l}{2}\right)=\frac{q_{\text {eff }}\left(12 E I-P l^{2}\right)\left(\sec \frac{K l}{2}-1\right)}{12 P}
$$

When $M(0)-M\left( \pm \frac{l}{2}\right)>0$, the break will occur at the middle of pressure bar, otherwise, the break will occur at two ends of the pressure bar.

The maximum normal stress on the cross-section is

$$
\sigma_{\max }=\frac{P}{A}-\frac{M y_{\max }}{I}
$$

Where $\sigma_{\max }=-\sigma_{t}, A$ is the cross section area, $A=1 \times h=h$.

$$
\begin{aligned}
& \text { If } M(0)-M\left( \pm \frac{l}{2}\right) \geq 0 \text {, thus, } y_{\max }=\frac{h}{2} \text { and } \\
& \left(12 q_{\text {eff }} E I-P q_{\text {eff }} l_{31}{ }^{2}\right) \sec \frac{K l_{31}}{2}=2 P h\left(P+\sigma_{t} h\right)+12 q_{\text {eff }} E I
\end{aligned}
$$

Otherwise, $y_{\max }=-\frac{h}{2}$ and

$$
l_{32}=h \sqrt{\frac{2\left(\sigma_{i h}+\sigma_{t}\right)}{q_{e f f}}}=h \sqrt{\frac{2 \sigma_{i h}}{q_{e f f}}+\frac{2 \sigma_{t}}{q_{\text {eff }}}} \geq h \sqrt{\frac{2 \sigma_{t}}{q_{\text {eff }}}}=l_{1}
$$

\subsubsection{Multi-layered Aquiclude}

When there are other rock strata between the aquifer and the coal seam, the equivalent elastic modulus $E_{\text {equ }}$ in Formula (43) can be derived based on an equivalent bending stiffness, and the inertia moment of the cross-section to the neutral axis $I_{\text {equ }}$ in Formula (43) is calculated by substituting the sum of each layer thickness.

\section{Case Study}

\subsection{Geological and Mining Conditions}

Permian System Shanxi formation (P1sh) $\mathrm{II}_{1}$ coal seam was exploited in 15031 panel in Jiulishan Coal mine, Jiaozuo Group, China. The floor strata consist of fine grained sandstone, limestone without water and mudstone (aquiclude) from top to bottom. Buried depth of the coal seam $\mathrm{H}$ is $400 \mathrm{~m}$, approved the average specific weight of overlying strata $\gamma$ is $2.5 \mathrm{MN} / \mathrm{m}^{3}, i=0.25$ and horizontal stress concentration factor $k$ is 3 , so the initial horizontal stress $\sigma_{\mathrm{h}}=10 \mathrm{MPa}$ based on the following equations.

$$
\sigma_{h}=k \sigma_{h i}=k \frac{\mu}{1-\mu} r H
$$

Main aquifers include $\mathrm{L}_{9}$ and $\mathrm{L}_{8}$ Ordovician limestone and the water pressure is $4 \mathrm{MPa}$. Thus $q_{\text {eff }}=3.69 \mathrm{MPa}$ approved the average specific weight of rock layers between coal seam and confined aquifer is also $2.5 \mathrm{MN} / \mathrm{m}^{3}$. Tensile strength of aquiclude is $2.4 \mathrm{MPa}$, and other mechanical parameters of floor strata were shown in Table 1. Based on these mechanical properties of strata in floor, the critical break length of aquiclude could be discussed.

Table 1. Mechanical Parameters of Floor Strata.

\begin{tabular}{llllll}
\hline Rock type & Thickness(m) & Cohesion(MPa) & Friction $\left({ }^{\circ}\right)$ & Inertia moment & Elastic module(GPa) \\
\hline Mudstone & 2.01 & 2.0 & 26 & 0.68 & 17.74 \\
Limestone & 1.00 & 5.0 & 36 & 0.08 & 18.95 \\
Siltstone & 9.50 & 7.5 & 30 & 71.45 & 4.00 \\
\hline
\end{tabular}




\subsection{Critical Break Length in Three Failure Modes}

(1) The critical break length in bending failure is calculated using Formula (9) as follow:

$$
l_{1} \geq \sum_{i=1}^{n} h_{i} \sqrt{\frac{2 \sigma_{t}}{q_{e f f}}}=12.51 \times \sqrt{\frac{2 \times 2.4}{3.69}}=14.27 \mathrm{~m}
$$

(2) For the critical break length in shear failure,

$$
A=\sum_{j=1}^{3}\left(\sigma_{\mathrm{h}} \tan \phi_{j}+c_{j}\right) h_{j}=152.19>0
$$

and

$$
B=-\sum_{j=1}^{3} \frac{q}{h^{3}}\left(\sum_{i=j+1}^{3} h_{i}-\sum_{i=1}^{j-1} h_{i}\right) h_{j} \tan \phi_{j}=1.46 \times 10^{-3}
$$

And thus, the critical break length in shear failure is calculated using Formula (23) as follow:

$$
l_{21}=\frac{q_{\text {eff }}-\sqrt{q_{\text {eff }}^{2}-16 A B}}{4 B}=\frac{3.69-\sqrt{3.69^{2}-16 \times 152.19 \times 1.46 \times 10^{-3}}}{4 \times 1.46 \times 10^{-3}}=42.76 \mathrm{~m}
$$

(3) Assumed the break occurs at the middle point of the pressure bar, the critical break length in deflection failure is calculated as follow:

$$
I_{\text {equ }}=\frac{\left(h_{1}+h_{2}+h_{3}\right)^{3}}{12}=163.15 \mathrm{~m}
$$

Based on an equivalent bending stiffness, elastic module can be calculated in following way,

$$
E_{\text {equ }}=\frac{1}{I} \sum_{i=1}^{3} E_{i} I_{i}=1.83 \mathrm{GPa}
$$

Based on Formula (43),

$$
l_{31}=34.48 \mathrm{~m}
$$

(4) Assumed a break occurs at either end of the pressure bar, the critical break length in deflection failure is calculated using Formula (44) as:

$$
l_{32}=h \sqrt{\frac{2\left(\sigma_{i h}+\sigma_{t}\right)}{q_{e f f}}}=12.51 \times \sqrt{\frac{2 \times(10+2.4)}{3.69}}=32.43 \mathrm{~m}
$$

Because $l_{32}<l_{31}, l_{32}$ is the more possible break length in buckling of pressure bar mode, $l_{32}$ will be used for comparison with other critical break lengths in bending failure mode and shear failure mode. From above calculation results, the break length in bending failure mode is smallest while the break length in shear failure mode is biggest. Therefore, it is more possible for water inrush from floor caused by bending break of aquiclude.

\subsection{Influencing Factors of $l_{1}, l_{21}, l_{32}$}

\subsubsection{Aquiclude Thickness}

According to the geological and mining conditions of Jiulishan coal mine, the relationships between $l_{1}, l_{21}, l_{32}$ and aquiclude thickness $h$ are shown in Figure 3. From Figure 3 we can see that these three critical break lengths increase and the increasing rate of critical break length in shear failure mode also increase with the aquiclude thickness. Therefore, it becomes difficult for water inrush from floor with the increase of the aquiclude thickness. Additionally, the critical shear break length is the biggest and the critical bending break length is the smallest under the same aquiclude thickness; the critical break length in buckling of pressure bar mode is bigger than the critical break length in bending failure mode for the function of horizontal stress, but it is smaller than the critical break length in shear failure mode.

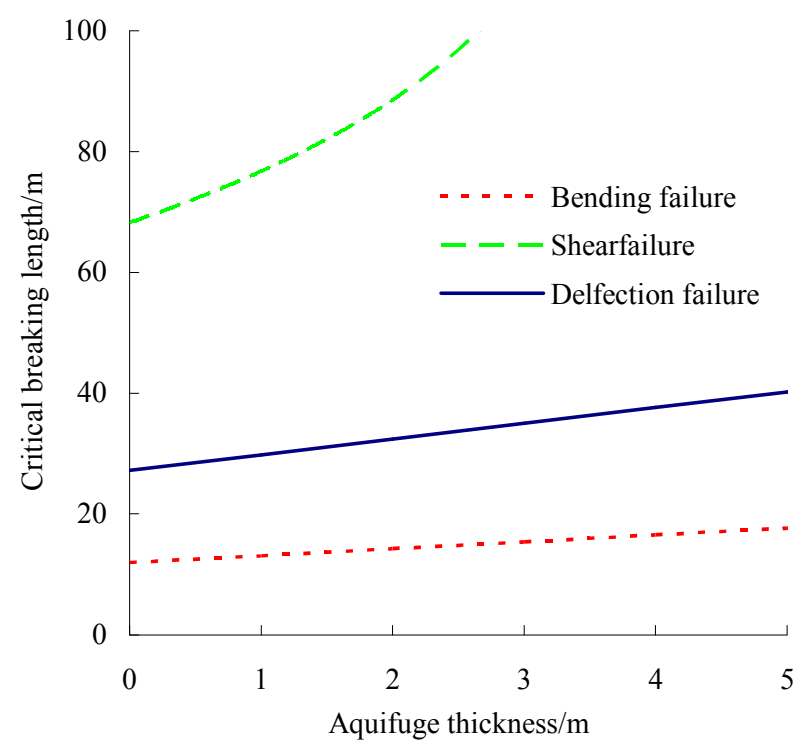

Figure 3. Relationships Between $l_{1}, l_{21}, l_{32}$ and Aquiclude Thickness $h$.

\subsubsection{Confined Aquifer Pressure}

The relationships between $l_{1}, l_{21}, l_{32}$ and confined aquifer pressure $q_{\text {eff }}$ are shown in Figure 4. From Figure 4 we can see that these three critical break lengths decrease and the decreasing rate of these three critical break lengths also decrease with the confined aquifer pressure. Therefore, it becomes easy for water inrush from floor occurs as increase of confined aquifer pressure. The critical shear break length in shear failure mode is the biggest and the critical break length in bending failure mode is the smallest under a same aquiclude thickness when confined aquifer pressure is lower than $12.46 \mathrm{MPa}$; the critical break length in buckling of pressure bar mode is bigger than the critical break length in bending failure mode for the function of horizontal stress, but it is smaller than the critical break length in shear failure mode until confined aquifer pressure is more than 12.46 MPa. But based on the geological conditions, water inrush from floor is more possible to occur because of the bending break of aquiclude and therefore, the water inrush type doesn't 
change with the variation of confined aquifer pressure.

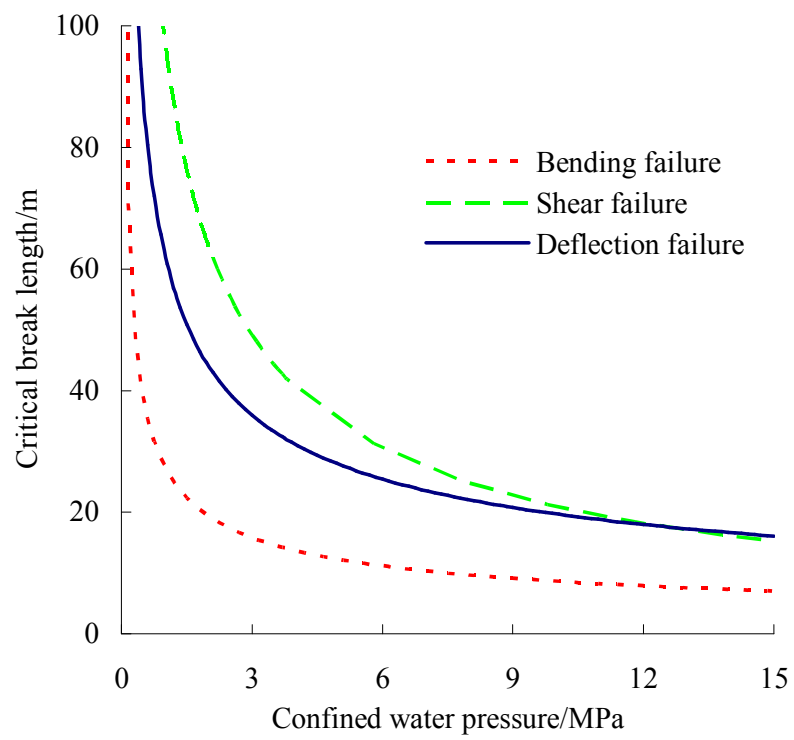

Figure 4. Relationships Between $l_{1}, l_{21}, l_{32}$ and Confined Aquifer Pressure $q_{\text {eff. }}$

\subsection{Control Technique of Avoiding Water Inrush from Floor Aquifer}

The caving roof would exert normal load on the floor after first weighting of the main roof, and thus the equivalent water pressure and aquiclude thickness achieve their critical values before the first weighting of the main roof. According to above results, water inrushes caused by break of aquiclude in three failure modes occur easily at two ends of beam before the first weighting of the main roof. That is to say, water inrush from "intact" floor usually happens at an open-off cut and a working face. The first weighting distance of the main roof in 15031 panel is about $34 \mathrm{~m}$, and a water inrush will occur for the bending break of floor aquiclude when the longwall mining distance reaches $14.27 \mathrm{~m}$ if there is no corresponding control technique.

Therefore control measures of lowering confined aquifer pressure and/or increasing aquiclude thickness should be conducted to avoid a water inrush into mining excavation from floor aquifer. When drainage is applied to decrease confined aquifer pressure, the confined aquifer pressure needs to be reduced to under $0.96 \mathrm{MPa}\left(q_{\text {eff }}=0.65 \mathrm{MPa}\right)$. But because Ordovician limestone water here is rich and has a wide range of hydraulic contact with the surrounding aquifer, it is hard to work when the control measure of drainage is used alone.

When grouting is used to increase the aquiclude thickness, the equivalent aquiclude thickness needs to be increased to above $19.31 \mathrm{~m}$. The sketch map of arrangement of grouting holes is shown in Figure 5. The basic principles of grouting are as follows: before mining advance, several drilling fields having a certain interval from each other are arranged in haulage gateway, then 3 5 grouting holes are drilled in the floor of entire panel from each drilling field. The karst fissure and water conducting fracture in confined aquifer will be filled by injected cement grout through grouting holes to greatly weaken the water rich property of the aquifer and to cut off most water supply channels with surrounding aquifer. Thus the rich aquifer can be transformed into an aquiclude or a weak aquifer, which helps improve the effect of lowering the pressure of confined aquifer by drainage, and ultimately benefits coal mining without water inrush.

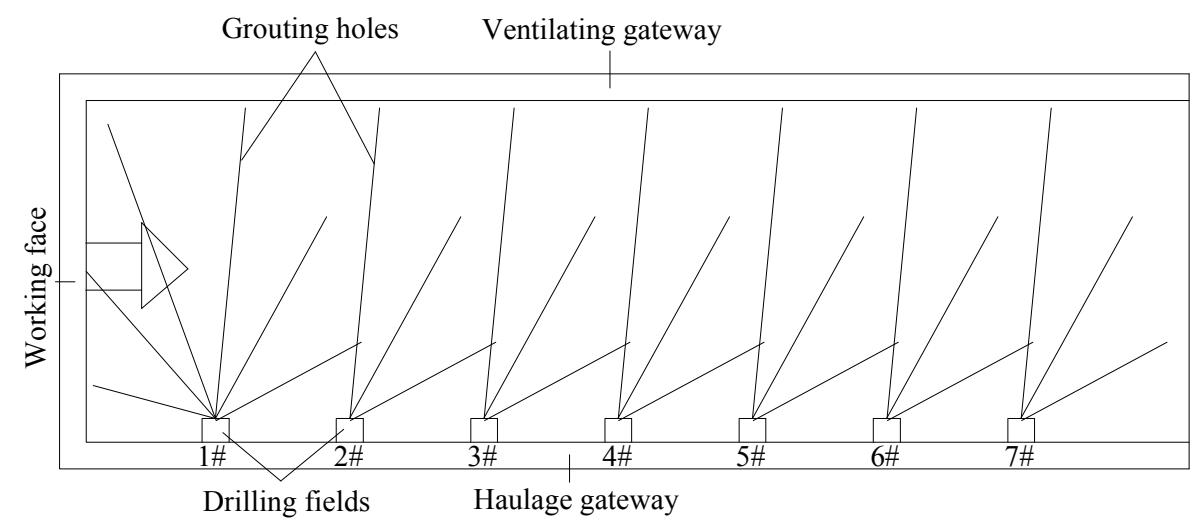

Figure 5. Sketch Map of Arrangement of Grouting Holes.

To be sure, if an artificial caving technique is used to shorten the first weighting distance of the main roof to below $14.27 \mathrm{~m}$, no other measures may need to be taken in theory to avoid water inrush from floor in mining process. But periodic weighting distance of the main roof (the average value is $13.5 \mathrm{~m}$ ) is near $14.27 \mathrm{~m}$, so that artificial caving technique is needed to ensure each periodic weighting distance of the main roof below $14.27 \mathrm{~m}$ and thus it can avoid water inrush from floor aquifer occurring in the whole mining process.

\section{Conclusions}

A mechanical model is established based on the aquiclude being simplified as the fixed - fixed beam under the uniform load. The critical break lengths of aquiclude in three failure modes including bending failure, shear failure and buckling 
of pressure bar are derived. These three critical break lengths increase and the increasing rate of the critical break length in shear failure mode also increases with the aquiclude thickness; these three critical break lengths decrease and the decreasing rates of these three critical break lengths also decrease with the confined aquifer pressure. According to the geological and mining conditions of Jiulishan coalmine, Jiaozuo group, critical break length of aquiclude in three failure modes including bending failure, shear failure and duckling failure of pressure bar are $12.47 \mathrm{~m}, 42.76 \mathrm{~m}, 32.43$ $\mathrm{m}$ respectively. Thus, water inrush may occur at the working face or open-off cut when the mining advance reaches 12.47 $\mathrm{m}$. Besides, three control measures are approved including lowering confined aquifer pressure by drainage, increasing aquiclude thickness by grouting and shortening the first weighting distance of the main roof by artificial caving. Sometimes it is difficult to work by using a single method, so it may be better to co-ordinate the use of above methods.

\section{Acknowledgements}

This research is supported by the China National Natural Science Foundation (Project Nos. 51109076) and the key scientific and technological project of Henan Province (152102210316).

\section{Conflicts of Interest}

The authors declare that there is no conflict of interest regarding the publication of this paper.

\section{References}

[1] HAN, J., et al., Mechanism of mine water-inrush through a fault from the floor. Mining Science and Technology (China), 2009. 19(3): p. 276-281.
[2] Li, H. M. and Fu, K., Some major technical problems and countermeasures for deep mining. Journal of Mining \& Safety Engineering, 2006(04): p.468-471. (in chinese).

[3] Wang, J. A. and Park, H. D. Coal mining above a confined aquifer. International Journal of Rock Mechanics and Mining Sciences, 2003. 40(4): p. 537-551.

[4] Zhang, J., Investigations of water inrushes from aquifers under coal seams. International Journal of Rock Mechanics and Mining Sciences, 2005. 42(3): p. 350-360.

[5] Yang, T. H., et al., A coupled flow-stress-damage model for groundwater outbursts from an underlying aquifer into mining excavations. International Journal of Rock Mechanics and Mining Sciences, 2007. 44(1): p. 87-97.

[6] KONG, H., et al., Analysis of the Harmfulness of Water-Inrush from Coal Seam Floor Based on Seepage Instability Theory. Journal of China University of Mining and Technology, 2007. 17(4): p. 453-458.

[7] Zhu, Q., et al., Numerical analysis of water inrush from working-face floor during mining. Journal of China University of Mining and Technology, 2008. 18(2): p. 159-163.

[8] Jiang, Z. H., Numerical analysis of the destruction of water-resisting strata in a coal seam floor in mining above aquifers. Mining Science and Technology (China), 2011. 21(4): p. 537-541.

[9] Jian, S., et al., Determining areas in an inclined coal seam floor prone to water-inrush by micro-seismic monitoring. Mining Science and Technology (China), 2011. 21(2): p. 165-168.

[10] Huang, Z., et al., Characterizing the hydraulic conductivity of rock formations between deep coal and aquifers using injection tests. International Journal of Rock Mechanics and Mining Sciences, 2014. 71: p. 12-18.

[11] Li, S., et al., Detecting and monitoring of water inrush in tunnels and coal mines using direct current resistivity method: A review. Journal of Rock Mechanics and Geotechnical Engineering, 2015. 7(4): p. 469-478. 